\title{
Comparison of bronchoconstriction induced by cycling and running
}

\author{
SANDRA D. ANDERSON, NICOLA M. CONNOLLY, \\ and S. G ODFRE Y ${ }^{1}$
}

Institute of Diseases of the Chest, Fulham Road, London S.W.3

\begin{abstract}
Bicycle ergometer, treadmill, and free range running exercise have been used to induce bronchoconstriction in 10 asthmatic subjects who were relatively well and free from symptoms at the time of study. Comparisons have been made with normal subjects under similar laboratory conditions. Bronchoconstriction was measured by peak expiratory flow rate before, during, and after each test. Ventilation, pulse rate, and gas exchange were also measured. The work involved in the different types of exercise was matched to produce similar ventilation and pulse rates for any one subject.

Exercise-induced bronchoconstriction was significantly less on the bicycle ergometer than on running (treadmill or free range). The normal subjects showed less than one quarter the bronchial lability of the asthmatic subjects in any one test. All subjects had lower respiratory exchange ratios during running compared with cycling and this appeared to correlate with the bronchial lability in the asthmatics, who also had rather higher pulse rates during running. Running involves a proportion of high-efficiency negative work which might partly account for the observed differences.
\end{abstract}

It is now well established that exercise may induce bronchoconstriction in asthmatic subjects (Jones, Buston, and Wharton, 1962). However, little attempt has been made to standardize the nature or quantity of exercise in the various studies. Although the test originally developed by Jones et al. (1962) involved free range running, exerciseinduced bronchoconstriction has been reported following stair climbing (Davies, 1968), and clinical experience suggests that swimming, tennis, and other forms of exercise may also provoke bronchoconstriction. Paradoxically cycling has been stated to be a poor method of inducing bronchoconstriction (Jones, Wharton, and Buston, 1963 ; Beaudry, Wise, and Seely, 1967) and we certainly obtained this impression ourselves.

Comparisons between different types of exercise are complicated by such factors as the difficulty in matching work and the different environments encountered in free running, stair climbing, and ergometer exercise in the laboratory. We therefore compared different types of exercise in asthmatic subjects under controlled conditions.

\footnotetext{
'Correspondence to Dr. S. Godfrey
}

\section{SUBJECTS AND METHODS}

Studies were made on 10 patients, three adults and seven children, all of whom had uncomplicated bronchial asthma according to the definition of Scadding (1966). Their physical characteristics areo given in Table I. All tests were made while the sub₹ jects were relatively well and not during acute attacks of asthma. In four subjects all tests were completed in three consecutive days and in the remainder theo

\section{T A B L E I}

BASIC DATA AND RESTING PEAK EXPIRATORY FLOW RATES IN 10 ASTHMATIC PATIENTS

\begin{tabular}{|c|c|c|c|c|c|c|}
\hline \multirow{2}{*}{ Subject } & \multirow{2}{*}{ Sex } & \multirow{2}{*}{$\begin{array}{l}\text { Age } \\
(\mathrm{yr})\end{array}$} & \multirow{2}{*}{$\begin{array}{l}\text { Height } \\
(\mathrm{cm})\end{array}$} & \multicolumn{3}{|c|}{ Resting PEF $^{1}$ ( $\%$ Expected) } \\
\hline & & & & Ergometer & Treadmill & Free Rang \\
\hline $\begin{array}{r}1 \\
2 \\
3 \\
4 \\
5 \\
6 \\
7 \\
8 \\
9 \\
10\end{array}$ & $\begin{array}{l}\mathbf{F} \\
\mathbf{M} \\
\mathbf{M} \\
\mathbf{F} \\
\mathbf{M} \\
\mathbf{F} \\
\mathbf{M} \\
\mathbf{M} \\
\mathbf{M} \\
\mathbf{F}\end{array}$ & $\begin{array}{r}8 \\
8 \\
9 \\
10 \\
12 \\
13 \\
15 \\
26 \\
27 \\
36\end{array}$ & $\begin{array}{l}124 \\
129 \\
128 \\
153 \\
145 \\
139 \\
161 \\
188 \\
167 \\
153\end{array}$ & $\begin{array}{r}97.8 \\
65.4 \\
69.2 \\
81.1 \\
80.1 \\
90.6 \\
119.5 \\
78.6 \\
44.0 \\
91.1\end{array}$ & $\begin{array}{r}82.9 \\
80.7 \\
69.0 \\
72.9 \\
58.0 \\
123.0 \\
100.0 \\
70.5 \\
68.8 \\
82.2\end{array}$ & $\begin{array}{r}102.0 \\
45.0 \\
48 \cdot 0 \\
87 \cdot 8 \\
92.5 \\
112.0 \\
97 \cdot 5 \\
87.5 \\
52.4 \\
102.5\end{array}$ \\
\hline
\end{tabular}

${ }^{1}$ The PEF is expressed as a percentage of the expected value and the resting value before each type of exercise test is given. 
tests were completed over a period of a few weeks, but care was taken that the patient's clinical condition was similar on each occasion. No patient was receiving corticosteroids at the time of study and none had received any sympathomimetic or other drug for at least 24 hours before the test. In addition some observations were made on six boys and five girls aged 7 to 14 years who were normal children from local schools, entirely free from asthma or other significant disease.

Each test consisted of steady state exercise for 6 minutes except for two tests in two adults which lasted 8 minutes. Exercise was performed in each of three ways in random order by each subject-

(a) seated on a cycle ergometer in the laboratory

(b) running on a treadmill in the laboratory

(c) free range running in a corridor for the children and around the hospital grounds for the adults.

Peak expiratory flow (PEF) was measured before and at 2-minute intervals during exercise and then for 15 minutes after stopping. The PEF was measured with a pneumotachograph (Fleisch No. 4) on the ergometer and treadmill and by a Wright peak flow meter which was calibrated against the pneumotachograph for the free range running. Pulse rate was recorded throughout electrocardiographically, being transmitted by a radiotelemeter (Parks Electronics) during free range running. The subjects all breathed through a respiratory valve of low resistance and dead space. and expired gas was continuously flushed through the circuit. Over the last minute of exercise, a gas collection was made in a Tissot spirometer for ergometer and treadmill exercise and in a light meteorological balloon carried on the back during free range running. Expired gas was analysed by the standard methods previously reported from this laboratory (Godfrey and Davies, 1970). End tidal $\mathrm{PCO}_{2}$ was monitored during ergometer and treadmill exercise with an infrared $\mathrm{CO}_{2}$ analyser but this was impractical during free range running.

An attempt was made to ensure that the rate of working was similar in each type of test by adjusting the work load or speed of running to produce similar ventilation and pulse rates for any one subject.

All ventilations are expressed at B.T.P.S. and all oxygen consumptions at S.T.P.D.

CALCUlation OF INDICES Exercise-induced bronchoconstriction was expressed for each test in three ways:

(a) the Jones lability index (Jones and Jones, 1966) is given by:

$$
\frac{\text { Highest PEF-Lowest PEF }}{\text { Expected normal PEF }} \times 100(\%)
$$

where the highest PEF was that obtained by any means (including the administration of a bronchodilator after completion of the test) and the lowest PEF was the lowest overall obtained whether during exercise or in the 15 minutes afterwards;

(b) the exercise lability index given by:

$$
\frac{\text { Highest exercise PEF-Lowest PEF }}{\text { Resting PEF }} \times 100(\%)
$$

where the highest exercise PEF was that obtained during exercise and the lowest was as in (a) above. When the subject's resting PEF was close to his expected PEF, the Jones lability index and exercise lability index are virtually identical, but this is not necessarily so in other circumstances ;

(c) the percent fall index which is the simplest index given by:

$$
\frac{\text { Resting PEF-Lowest PEF }}{\text { Resting PEF }} \times 100(\%)
$$

where the lowest PEF was as in (a) above. Normal values for PEF were taken from our own studies in this laboratory (Godfrey, Kamburoff, and Nairn, 1970).

\section{RESULTS}

A typical record showing bronchoconstriction induced by the three different types of exercise is given in Fig. 1 for subject 7 . It can be seen

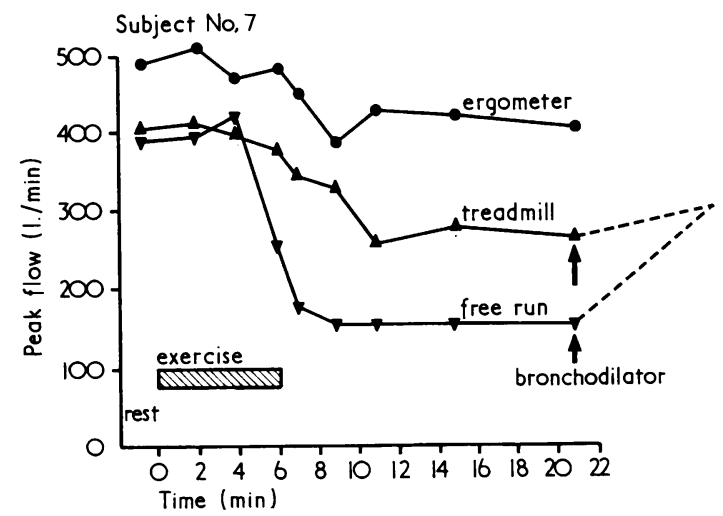

FIG. 1. Response to three types of exercise in one subject.

that the free range (corridor) running produced more constriction than the treadmill, while the ergometer produced very little. The resting levels of PEF in this subject were all within 1 S.D. of his expected normal value of $435 \mathrm{l}$./minute. Constriction began during the last 2 minutes of ergometer or corridor exercise and reached its maximum from 3 to 5 minutes after stopping.

This difference in the degree of bronchoconstriction was observed in all but two of the patients, free range running being the most effective and ergometer exercise the least effective method of causing the bronchoconstriction. The 
T A B L E I I

INDIVIDUAL RESULTS FOR ASTHMATIC SUBJECTS

\begin{tabular}{|c|c|c|c|c|c|c|c|c|c|}
\hline \multirow{2}{*}{ Subject } & \multicolumn{3}{|c|}{ Jones Lability Index $(\%)$} & \multicolumn{3}{|c|}{ Exercise Lability Index (\%) } & \multicolumn{3}{|c|}{ Fall Index $(\%)$} \\
\hline & $\begin{array}{c}\text { Cycle } \\
\text { Ergometer }\end{array}$ & Treadmill & Free Run & $\begin{array}{c}\text { Cycle } \\
\text { Ergometer }\end{array}$ & Treadmill & Free Run & $\begin{array}{c}\text { Cycle } \\
\text { Ergometer }\end{array}$ & Treadmill & Free Run \\
\hline $\begin{array}{r}1 \\
2 \\
3 \\
4 \\
5 \\
5 \\
7 \\
8 \\
9 \\
10\end{array}$ & $\begin{array}{l}44 \cdot 5 \\
17 \cdot 0 \\
48 \cdot 0 \\
13 \cdot 0 \\
37 \cdot 0 \\
33 \cdot 0 \\
22 \cdot 2 \\
50 \cdot 5 \\
14 \cdot 8 \\
72 \cdot 0\end{array}$ & $\begin{array}{l}58 \cdot 0 \\
47 \cdot 5 \\
56 \cdot 0 \\
15 \cdot 0 \\
42 \cdot 0 \\
31 \cdot 0 \\
41 \cdot 5 \\
52 \cdot 0 \\
28 \cdot 0 \\
91 \cdot 5\end{array}$ & $\begin{array}{l}58 \cdot 5 \\
30 \cdot 0 \\
34 \cdot 5 \\
46 \cdot 0 \\
40 \cdot 0 \\
69 \cdot 0 \\
60 \cdot 0 \\
69 \cdot 0 \\
41 \cdot 0 \\
73 \cdot 5\end{array}$ & $\begin{array}{l}37 \cdot 0 \\
26 \cdot 5 \\
53 \cdot 0 \\
16 \cdot 4 \\
44 \cdot 0 \\
36 \cdot 0 \\
26 \cdot 5 \\
64 \cdot 0 \\
37 \cdot 0 \\
79 \cdot 0\end{array}$ & $\begin{array}{r}46 \cdot 0 \\
38 \cdot 5 \\
68 \cdot 0 \\
24.0 \\
57.0 \\
25 \cdot 0 \\
41 \cdot 5 \\
73.0 \\
40.0 \\
111.0\end{array}$ & $\begin{array}{l}50 \cdot 0 \\
45 \cdot 0 \\
72 \cdot 0 \\
52 \cdot 0 \\
40 \cdot 0 \\
57 \cdot 0 \\
67 \cdot 0 \\
79 \cdot 0 \\
78 \cdot 0 \\
72 \cdot 0\end{array}$ & $\begin{array}{r}26 \cdot 0 \\
12 \cdot 0 \\
0 \cdot 0 \\
8 \cdot 0 \\
37 \cdot 0 \\
24 \cdot 0 \\
22 \cdot 2 \\
18 \cdot 0 \\
14 \cdot 8 \\
40 \cdot 0\end{array}$ & $\begin{array}{r}28.0 \\
40.0 \\
8.4 \\
11.0 \\
43.0 \\
23.0 \\
39.0 \\
25.0 \\
33.0 \\
79.0\end{array}$ & $\begin{array}{l}50 \cdot 0 \\
30 \cdot 0 \\
12 \cdot 0 \\
47 \cdot 5 \\
34 \cdot 0 \\
56 \cdot 0 \\
63 \cdot 0 \\
61 \cdot 0 \\
61 \cdot 0 \\
67 \cdot 0\end{array}$ \\
\hline
\end{tabular}

Each method of calculating bronchial lability as described in the text has been used for each type of exercise.

individual results for the three indices are given in Table II and the group results in Fig. 2 which includes the available results for normal subjects. With all three indices the differences between types of exercise in the asthmatic subjects were highly significant. Using the paired $t$ test for exercise-induced bronchoconstriction on the ergometer and free running the probability of the differences being due to chance was less than $0 \cdot 005$. Likewise all the three indices were significantly different $(\mathrm{P}<0.01)$ for bronchoconstriction

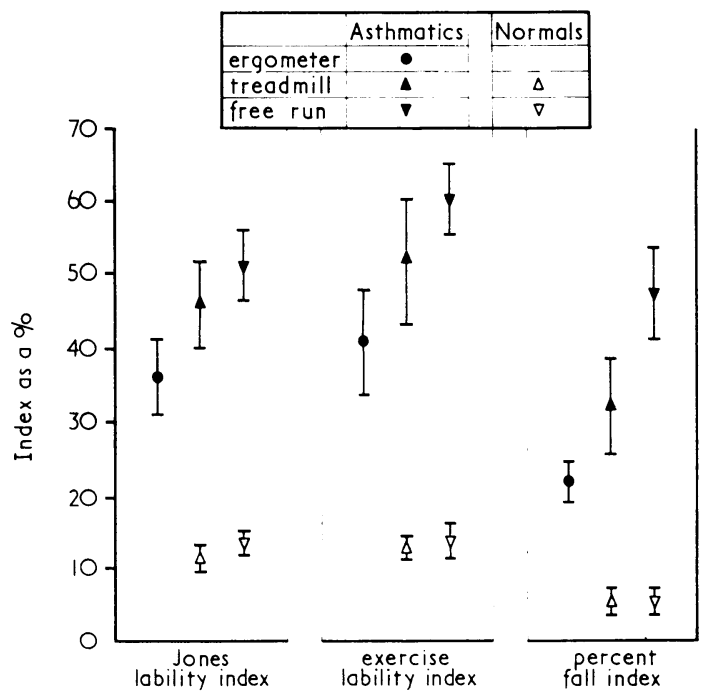

FIG. 2. Bronchial lability in different types of exercise in asthmatic and normal subjects. The derivation of the indices of lability is described in the text. The normal group included the nine subjects described in Table IV and two others who did not have gas collections: lability was not studied during ergometer exercise. The points represent the means for each group and the limits indicate one standard error. induced by the bicycle ergometer compared witho the treadmill. The differences between the treadmill and free range running were not significantc for the Jones or exercise lability indices, but the percent fall index was significantly different $\vec{\bullet}$ $(P<0.01)$. This implies that free range running $\triangle$ produces a greater fall from the resting level than the treadmill, but the rise during or after exerciseo is more variable.

The matching of work and ventilation and the mean values for lability in the three types of $\frac{0}{\mathscr{Q}}$ exercise are shown in Table III. Since the subjects $\varrho$ varied considerably in size the individual results $\overrightarrow{0}$ showed considerable scatter, but since each sub- 3 ject served as his own control, the mean values? for the group could be compared and a paired? $t$ test used to assess significance. In fact the only significant difference in all the data shown in Table III besides the lability indices discussed $x$ above was for respiratory exchange ratio $(R)$ com- $\frac{0}{3}$ paring the ergometer test to either the treadmillor free range running. Comparable results in the group of normal subjects are given in Table IV. There was very little bronchial lability and it was옥 less than one quarter of that seen in the asth- $\rightarrow$ matics by whatever index it was assessed. It was not studied on the ergometer in this group. On $\tilde{\sigma}$ the basis of the oxygen consumption the level of work performed in the corridor (which produced the highest lability) was similar in the normals $\omega$ compared to the asthmatics but it was rather lower on the treadmill. There were no significanto differences in end-tidal $\mathrm{PCO}_{2}$ between normals and $\Phi$ asthmatics. Pulse rates could be compared only ${ }^{+}$ by predictions based on height and oxygen consumption (Godfrey, Davies, Wozniak, and Barnes, $\frac{O}{\mathbb{D}}$ in preparation) since the normals and asthmatics?

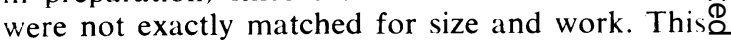
showed that whereas there was no difference in pulse rates in relation to the type of exercise in asthmatics, they were significantly higher on theo 
T A B L E I I I

GROUP RESULTS FOR ASTHMATIC SUBJECTS

\begin{tabular}{|c|c|c|c|c|c|c|c|c|c|}
\hline & \multicolumn{3}{|c|}{ Ergometer } & \multicolumn{3}{|c|}{ Treadmill } & \multicolumn{3}{|c|}{ Free Run } \\
\hline & Mean & S.E.M. & $\mathbf{n}$ & Mean & S.E.M. & $\mathbf{n}$ & Mean & S.E.M. & $\mathbf{n}$ \\
\hline $\begin{array}{l}\text { Jones lability index } \\
\text { Exercise lability index } \\
\text { Percent fall index }\end{array}$ & $\begin{array}{l}36 \cdot 1 \\
41 \cdot 9 \\
20 \cdot 2\end{array}$ & $\begin{array}{l}5 \cdot 90 \\
5 \cdot 96 \\
3 \cdot 90\end{array}$ & $\begin{array}{l}10 \\
10 \\
10\end{array}$ & $\begin{array}{l}46 \cdot 2 \\
52 \cdot 4 \\
32 \cdot 9\end{array}$ & $\begin{array}{l}6 \cdot 6 \\
8 \cdot 3 \\
6 \cdot 3\end{array}$ & $\begin{array}{l}10 \\
10 \\
10\end{array}$ & $\begin{array}{l}52 \cdot 1 \\
61 \cdot 2 \\
48 \cdot 1\end{array}$ & $\begin{array}{l}5 \cdot 0 \\
4 \cdot 5 \\
5 \cdot 6\end{array}$ & $\begin{array}{l}10 \\
10 \\
10\end{array}$ \\
\hline $\begin{array}{l}\mathrm{VO}_{2} \\
\mathrm{VE} \\
\mathrm{VE}_{/} \mathrm{VO}_{2} \\
\mathrm{PETCO} \\
\mathrm{R} \\
\text { Pulse rate } \\
\text { Pulse }\end{array}$ & $\begin{array}{c}1470 \\
50 \cdot 3 \\
36 \cdot 2 \\
28 \cdot 0 \\
0 \cdot 96 \\
164 \\
96 \cdot 3\end{array}$ & $\begin{array}{l}224 \\
\quad 6 \cdot 6 \\
4 \cdot 0 \\
2 \cdot 1 \\
0.035 \\
7 \cdot 0 \\
3 \cdot 1\end{array}$ & $\begin{array}{l}10 \\
10 \\
10 \\
10 \\
10 \\
10 \\
10\end{array}$ & $\begin{array}{c}1636 \\
48 \cdot 7 \\
30 \cdot 8 \\
29 \cdot 0 \\
0 \cdot 88 \\
175 \\
101 \cdot 5\end{array}$ & $\begin{array}{l}310 \\
7.6 \\
1.0 \\
1.6 \\
0.025 \\
3 \cdot 0 \\
4 \cdot 1\end{array}$ & $\begin{array}{l}10 \\
10 \\
10 \\
10 \\
10 \\
10 \\
10\end{array}$ & $\begin{array}{c}1669 \\
49 \cdot 1 \\
30 \cdot 7 \\
- \\
0 \cdot 84 \\
180 \\
98 \cdot 7\end{array}$ & $\begin{array}{l}276 \\
6.2 \\
1.4 \\
\overline{0} .027 \\
4.0 \\
3.6\end{array}$ & $\begin{array}{l}10 \\
10 \\
10 \\
- \\
10 \\
10 \\
10\end{array}$ \\
\hline
\end{tabular}

The bronchial lability indices are given above and the ventilation, pulse rate, and gas exchange are given below. Pulse has also been expressed as a percentage of the expected value based on $\mathrm{VO}_{2}$, height, and sex for ergometer exercise. ( Vo $2=0 x y g e n$ consumption, $\mathrm{VE}_{2}=$ minute ventilation, $\mathrm{PETCO}_{2}=$ end-tidal $\mathrm{PCO}_{2}$-not obtained during free range running)

T A B L E I V

GROUP RESULTS FOR NORMAL SUBJECTS

\begin{tabular}{|c|c|c|c|c|c|c|c|c|c|}
\hline & \multicolumn{3}{|c|}{ Ergometer } & \multicolumn{3}{|c|}{ Treadmill } & \multicolumn{3}{|c|}{ Free Run } \\
\hline & Mean & S.E.M. & n & Mean & S.E.M. & $n$ & Mean & S.E.M. & $\mathbf{n}$ \\
\hline $\begin{array}{l}\text { Jones lability index } \\
\text { Exercise lability index } \\
\text { Percent fall index }\end{array}$ & & & & $\begin{array}{r}9 \cdot 4 \\
11 \cdot 0 \\
5 \cdot 1\end{array}$ & $\begin{array}{l}1 \cdot 3 \\
1 \cdot 5 \\
1.9\end{array}$ & $\begin{array}{l}9 \\
9 \\
9\end{array}$ & $\begin{array}{r}14 \cdot 1 \\
15 \cdot 4 \\
6 \cdot 4\end{array}$ & $\begin{array}{l}1.9 \\
2 \cdot 4 \\
1 \cdot 4\end{array}$ & $\begin{array}{l}9 \\
9 \\
9\end{array}$ \\
\hline $\begin{array}{l}\mathrm{VO}_{2} \\
\mathrm{VE} \\
\mathrm{VE} / \mathrm{Vo}_{2} \\
\text { PETCO, } \\
\mathrm{R} \\
\text { Pulse rate } \\
\text { Pulse }{ }_{0} \text { expected }\end{array}$ & $\begin{array}{c}1034 \\
35 \cdot 1 \\
35 \cdot 6 \\
30 \cdot 3 \\
1 \cdot 10 \\
182 \\
106 \cdot 5\end{array}$ & $\begin{array}{l}132 \\
3.0 \\
2 \cdot 1 \\
1.6 \\
0.017 \\
6.0 \\
2.46\end{array}$ & $\begin{array}{l}9 \\
9 \\
9 \\
8 \\
7 \\
9 \\
9\end{array}$ & $\begin{array}{c}1205 \\
37 \cdot 6 \\
32 \cdot 8 \\
30 \cdot 3 \\
0 \cdot 91 \\
175 \cdot 5 \\
101\end{array}$ & $\begin{array}{l}166 \\
3 \cdot 98 \\
2 \cdot 68 \\
2 \cdot 1 \\
0.016 \\
4 \cdot 0 \\
3 \cdot 03\end{array}$ & $\begin{array}{l}9 \\
9 \\
9 \\
9 \\
9 \\
9 \\
9\end{array}$ & $\begin{array}{c}1478 \\
44 \cdot 6 \\
31.9 \\
- \\
0.90 \\
173 \\
90.3\end{array}$ & $\begin{array}{l}200 \\
4 \cdot 5 \\
2 \cdot 4 \\
\overline{0} \cdot 030 \\
5 \cdot 0 \\
2 \cdot 3\end{array}$ & $\begin{array}{l}9 \\
9 \\
9 \\
9 \\
9 \\
9 \\
9\end{array}$ \\
\hline
\end{tabular}

Results as in Table III but bronchial lability was not measured during ergometer exercise in these subjects.

ergometer compared with free running or the treadmill in normals.

\section{DISCUSSION}

This study has positively confirmed the clinical impression that running causes greater bronchoconstriction than cycling in asthmatic subjects.

Studies of this kind, by the very nature of asthma, are difficult to standardize. We attempted to avoid the natural variation in the disease by studying patients either over a very short space of time or while they were in similar clinical states. The difference in lability for the various types of exercise was not related to the resting PEF and was consistent despite the random order of the tests. This makes it highly unlikely that the differences were due to variations in the patient's condition.

Most asthmatic patients are sensitive to house dust and many also complain that cold provokes bronchospasm (Hsieh, Frayser, and Ross, 1968). Running in the corridor or in the open air could have exposed our patients to such factors, but the difference between cycling and running was almost as great when the running was performed on a treadmill. This apparatus was physically substituted for the ergometer and the identical respiratory circuit was used in the laboratory and hence environmental factors were largely excluded. Differences between treadmill and free range running were small as measured by the Jones and exercise labilities.

No real quantitative data are available on the exercise needed to provoke bronchoconstriction. However, Beaudry et al. (1967) did not obtain bronchoconstriction with ergometer exercise in children at oxygen consumptions of the order of $600 \mathrm{ml} /$ minute. Irnell and Swartling (1966) did obtain exercise-induced bronchoconstriction with ergometer exercise in adults, but they used progressively hard levels of exercise for a maximum of 18 minutes, the last load $(900 \mathrm{kpm} / \mathrm{min})$ being equivalent to an oxygen consumption of 2,100 $\mathrm{ml} /$ minute. Even so, it is possible to calculate the mean exercise lability index from their data which 
was approximately $25 \%$ for the whole series and $40 \%$ for their more severely affected group. These figures are not unlike our ergometer results and certainly show less lability than our treadmill or free running studies. These facts suggest that absolute work load (or duration) may be important for the production of bronchoconstriction on the ergometer but this does not account for the differences in our study between types of exercise.

The only differences we noted in the parameters measured, besides PEF, was a lower respiratory exchange ratio $(R)$ in the running compared with the ergometer. Indeed there seemed to be a direct relationship between the fall of PEF ( $\%$ fall index) and the R (Fig. 3) for all but

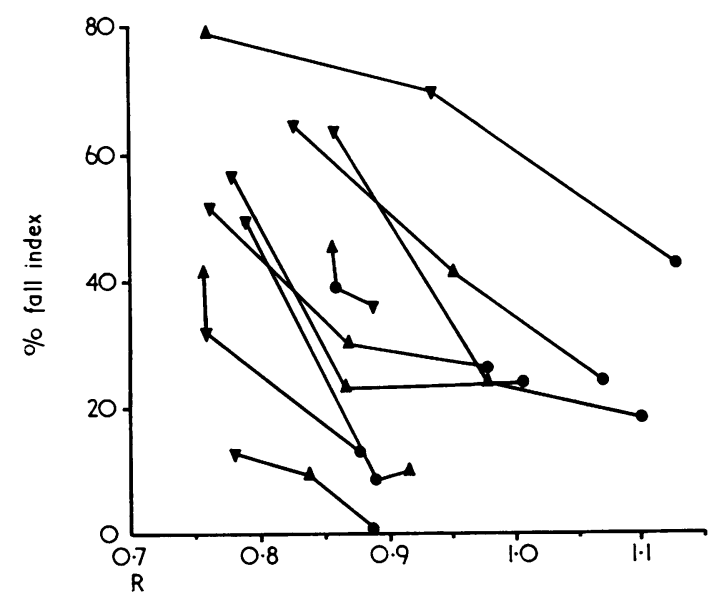

FIG. 3. Relationship between the percentage fall in peak expiratory flow rate and the respiratory exchange ratio $(R)$ of exercise. The symbols are the same as those in Figures 1 and 2.

one subject who showed the opposite effect. It even appeared that the $\mathbf{R}$ was more important than whether the running was treadmill or free range. We noted that our normal subjects had lower $\mathbf{R}$ values during running compared with cycling and similarly low $R$ values can be calculated for normal adults on a treadmill (Hanson, Tabakin, and Levy, 1967) compared with an ergometer (Naimark, Wasserman, and McIlroy, 1964). In fact our asthmatic patients had lower $\mathbf{R}$ values than the normals for comparable types of exercise. Their changes in $\mathbf{R}$ may reflect changes in blood lactate and acid-base balance but this needs considerable clarification because of the conflicting published results. Thus Beaudry et al. (1967) reported base deficits of the order of $-8 \mathrm{mEq} / 1$. with arterial $\mathrm{PCO}_{2}$ values of $32 \mathrm{mmHg}$, represent ing severe metabolic (?lactic) acidosis during ergo을 meter exercise, without obtaining bronchocon 흘 striction. On the other hand, Seaton, Davies? Gaziano, and Hughes (1969) reported similaㅁ levels of acidosis with high measured lactates after free range running which did result in bronchoconstriction. The two studies suggest that it is the nature of the exercise rather than the level of acidosis or lactate which causes bronchos constriction. We are planning to study these्र variables in relation to the type of exercisen because the data suggest that acidosis associated with a low $\mathbf{R}$ (Fig. 3) is more likely than anythin else to cause bronchoconstriction.

Many other factors which could have accounted for differences in bronchoconstriction produced by unquantitated cycling or running have beer excluded by the design of the present study. These include end tidal $\mathrm{PCO}_{2}$ and total minute ventila tion which was virtually identical in running and cycling. Thus bronchoconstriction provoked by hypocapnic hyperventilation (Crompton, 1968 was not responsible for our observed differencesWe may postulate that some other, as yef unknown, factor is operating more during running than cycling. One possibility is that the genera level of neural activity is greater during running and here one may note that there is a consider able component of negative or eccentric work in running but not cycling. Negative work is per formed when energy is absorbed by muscles a옹 they are stretched during contraction. During running, energy is released as the centre of graviti, of the body falls at the end of each step. Some of this kinetic energy is absorbed by leg muscles in landing. Since the mechanical efficiency for negative work is much higher than for positive work (Kamon, 1970) the muscles of our subjects were actually involved in more physical work fog. the same oxygen consumption during running compared with cycling.

We must conclude that as yet we have foun no definite explanation for the greater ability of running to cause bronchoconstriction compare with cycling, but some obvious possibilities have been excluded and others suggested by the presen study.

\section{REFERENCES}

Beaudry, P. H., Wise, M. B., and Seely, J. E. (1967). Respir椐 tory gas exchange at rest and during exercise in norma and asthmatic children. Amer. Rev. resp. Dis., 95, 248

Crompton, G. K. (1968). An unusual example of exercise induced asthma. Thorax, 23, 165. 
Davies, S. E. (1968). Effect of disodium cromoglycate on exercise-induced asthma. Brit. med. J., 3, 593.

Godfrey, S., and Davies, C. T. M. (1970). Estimates of arterial $\mathrm{PCO}_{2}$ and their effect on the calculated values of cardiac output and dead space on exercise. Clin. Sci., 39, 529.

- Kamburoff, P. L., and Nairn, J. R. (1970). Spirometry, lung volumes and airway resistance in normal children aged 5 to 18 years. Brit. J. Dis. Chest., 64, 15.

Hanson, J. S., Tabakin, B. S., and Levy, A. M. (1967). Exercise arterial blood gas and end-tidal gas changes during acute airway obstruction. Resp. Physiol., 3, 64.

Hsieh, Y-C., Frayser, R., and Ross, J. C. (1968). The effect of cold-air inhalation on ventilation in normal subjects and in patients with chronic obstructive pulmonary disease. Amer. Rev. resp. Dis., 98, 613.

Irnell, L., and Swartling, S. (1966). Maximal expiratory flow at rest and during muscular work in patients with bronchial asthma. Scand. J. resp. Dis., 47, 103.
Jones, R. H. T., and Jones, R. S. (1966). Ventilatory capacity in young adults with a history of asthma in childhood. Brit. med. J., 2, 976.

Jones, R. S., Buston, M. H., and Wharton, M. J. (1962). The effect of exercise on ventilatory function in the child with asthma. Brit. J. Dis. Chest, 56, 78.

W Wharton, M. J., and Buston, M. H. (1963). The place of physical exercise and bronchodilator drugs in the assessment of the asthmatic child. Arch. Dis. Child,. 38, 539.

Kamon, E. (1970). Negative and positive work in climbing a laddermill. J. appl. Physiol., 29, 1.

Naimark, A., Wasserman, K., and McIlroy, M. B. (1964). Continuous measurement of ventilatory exchange ratio during exercise. J. appl. Physiol., 19, 644.

Scadding, J. G. (1966). Patterns of respiratory insufficiency. Lancet, 1, 701.

Seaton, A., Davies, G., Gaziano, D., and Hughes, R. O. (1969). Exercise-induced asthma. Brit. med. J., 3, 556. 